\title{
PERCEPCIÓN DE AMENAZAS EN UNA PEQUEÑA COMUNIDAD COSTERA DE PATAGONIA (ARGENTINA)
}

\section{PERCEPTION OF HAZARDS TO A SMALL PATAGONIAN COASTAL COMMUNITY (ARGENTINE)}

\author{
Dra. María Paula Ferrari \\ Becaria de Postgrado del CONICET \\ Docente del Instituto de Investigaciones Geográficas de la Patagonia (IGEOPAT), Universidad \\ Nacional de la Patagonia San Juan Bosco, sede Trelew.
}

\section{Resumen}

El objetivo del trabajo es analizar la percepción de amenazas vinculadas a procesos de erosión costera en la comunidad de Playa Magagna (Provincia de Chubut, Patagonia Argentina). Mediante un muestreo probabilístico estratificado, basado en el criterio de heterogeneidad espacial, se identificaron cuatro subuniversos de análisis asociados a las unidades geomorfológicas principales sobre las que se asienta la urbanización. En cada subuniverso se realizaron encuestas personales a residentes permanentes y transitorios del área de estudio. En el proceso de gestión de riesgos, la opinión de la comunidad afectada debe ser considerada al momento de brindar soluciones a problemas costeros de este tipo.

Palabras clave: Percepción Social del Riesgo; Amenazas; Costas; Patagonia.

\begin{abstract}
The goal of this task is to assess the perception of hazards linked to coastal erosion in the sea-side community of Playa Magagna (Chubut Province, Argentine Patagonia). Four study subuniverses linked to the main geomorphological units located within this area- have been identified by means of a stratified probability sampling based on its spatial heterogeneity. Surveys have been carried out among permanent as well as temporary residents. The results of said surveys must be taken into account in the process of finding and applying solutions to this kind of coastal issue.
\end{abstract}

Keywords: Social Perception of Risk; Hazards; Shores; Patagonia.

\section{Introducción}

Las continuas transformaciones y lógicas particulares de organización que experimentan los territorios, como consecuencia de las intervenciones que las sociedades realizan sobre los mismos, produce cambios tanto en los sistemas naturales como sociales. En este contexto, se configuran diversas problemáticas ambientales, entre las que se encuentran las vinculadas a los riesgos.

El rápido e inadecuado estilo de crecimiento de las ciudades contemporáneas ha planteado nuevos retos a la investigación sobre la construcción social del riesgo en el ámbito urbano. En este sentido, ha adquirido importancia el estudio del proceso de urbanización como una de las principales actividades antrópicas que impactan o transforman el territorio; del cual las áreas litorales no están exentas. Por lo tanto, en la dinámica costera no sólo intervienen procesos naturales sino también actuaciones sociales, que en ciertas ocasiones construyen situaciones de riesgo. 
Figura 1. Localización de Playa Magagna (Chubut, Argentina)
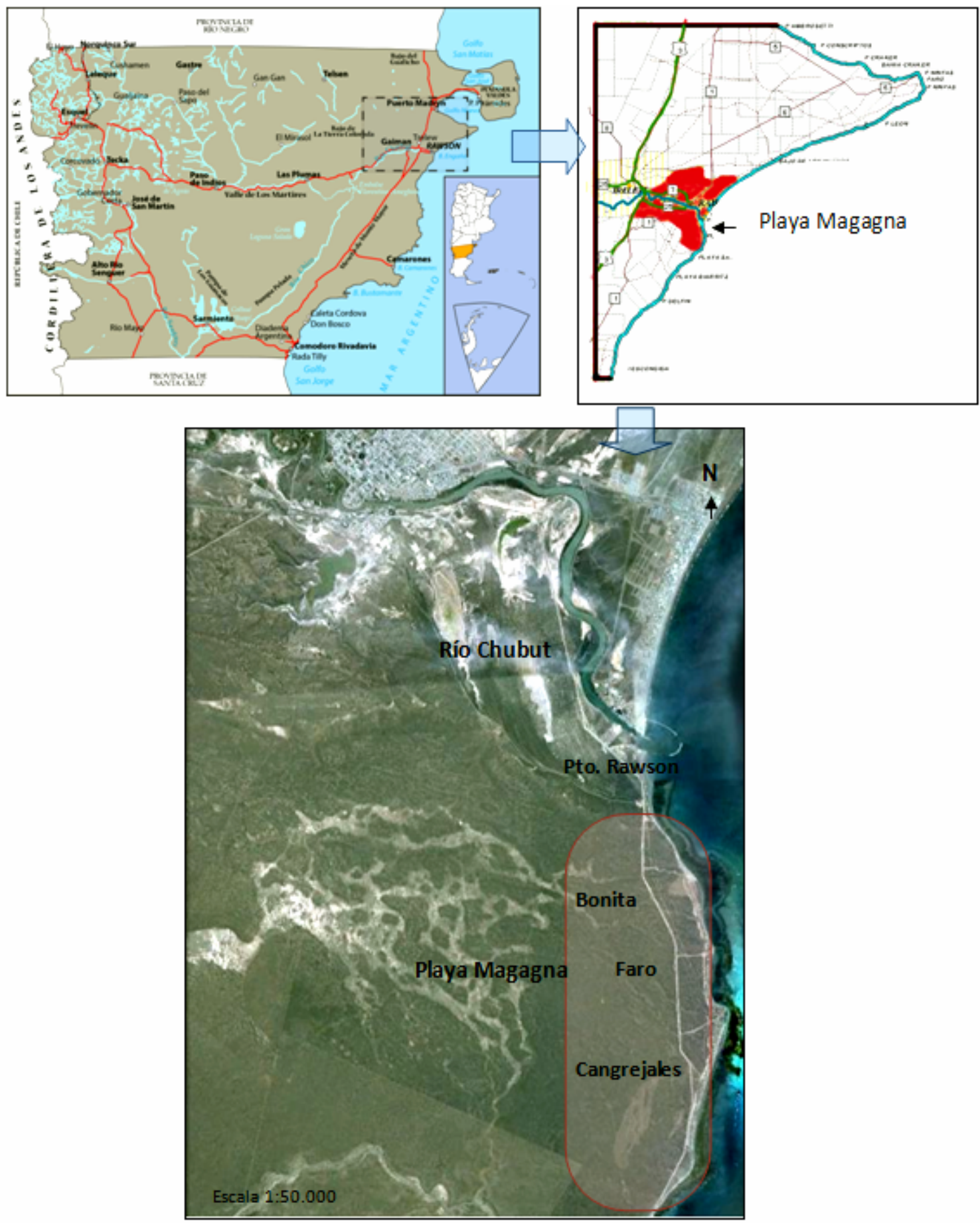

Fuente: M.P. Ferrari (2012) sobre la base de imagen Google Earth 2009 y cartografía del Instituto Geográfico Nacional. 
Revista Geográfica Digital. IGUNNE. Facultad de Humanidades. UNNE. Año 10. № 19. Enero - Junio 2013.

El objetivo del presente trabajo es analizar la percepción que la comunidad costera de Playa Magagna construye respecto a las amenazas vinculadas a los procesos de erosión costera presentes en el sitio.

Playa Magagna se localiza en el sector noreste de la Provincia de Chubut (Patagonia, Argentina) al sur de la desembocadura del río homónimo sobre el litoral marítimo (ver figura 1). Corresponde a una angosta franja de costa de aproximadamente $6 \mathrm{~km}$ de largo, conformada por tres pequeños asentamientos costeros: Bonita, El Faro y Los Cangrejales, que en los últimos años han evidenciado un importante crecimiento para uso residencial, de ocio y turismo.

El avance de la urbanización registrado en los últimos años ha contribuido a configurar situaciones de riesgo en el sector, a partir de la presencia de procesos naturales y antrópicos de peligro (amenazas) y la manifestación de condiciones de vulnerabilidad en los elementos del medio social y construido ya expuestos.

El área presenta diversos procesos geomorfológicos vinculados con el retroceso de la costa por erosión marina, y con los derrumbes de las barrancas occidentales por erosión hídrica-pluvial y remoción en masa. Todos ellos se constituyen en procesos de la dinámica costera que según la perspectiva humana pueden ser considerados como amenazas o peligros.

Si bien existen amenazas naturales, la creciente ocupación del espacio generó diversas modificaciones en el ambiente costero, que han contribuido a acentuar los procesos naturales ya existentes en el área, y como consecuencia, manifiestan la presencia de amenazas socio-naturales o antrópicas. Por lo tanto, la intervención humana no sólo ha modificado la dinámica de los procesos costeros, y con ello su peligrosidad potencial, sino también ha impactado en las condiciones de vulnerabilidad del medio social.

\section{Marco conceptual: vinculaciones entre riesgo, percepción y territorio.}

El riesgo corresponde al grado de pérdidas o daños esperados debido a la ocurrencia de un fenómeno natural o antrópico peligroso desde la perspectiva humana (amenaza), y a las condiciones de vulnerabilidad de los elementos expuestos a dicho fenómeno (Cardona, 1993).

Se considera peligrosidad o amenaza a la probabilidad de ocurrencia de un fenómeno natural o antrópico, que puede presentarse en un sitio específico y en un tiempo determinado, produciendo efectos adversos en personas, bienes o medio ambiente (Cardona, 1993). Si bien, no todos los fenómenos son considerados peligrosos, lo son aquellos que presentan la posibilidad de ocasionar daños o perjuicios a la sociedad. Como señalan Romero y Maskrey (1993), la peligrosidad de un fenómeno se refiere a la potencialidad de daño del mismo.

Las amenazas de origen natural se definen como aquellas manifestaciones de procesos de la naturaleza vinculadas a la dinámica geológica, geomorfológica, climática u oceánica en las cuales no existe intervención humana directa o significativa posible (Lavell, 1996).

Por otro lado, los procesos naturales suelen tener una expresión o incidencia que es socialmente inducida, es decir, se producen o bien se acentúan por algún tipo de intervención humana, a las que denominamos amenazas socio-naturales o inducidas antrópicamente. En la mayoría de los casos suelen confundirse con eventos propiamente naturales, como ocurre con los 
deslizamientos, hundimientos, inundaciones, incendios rurales o agotamiento de acuíferos (Lavell, 1996).

La percepción que un grupo humano realiza del espacio o territorio en que se desenvuelve, así como la imagen que construye del mismo, es el resultado de la superposición y acumulación de percepciones e imágenes individuales. Como sostiene Caneto (2000) "si bien cada persona percibe el espacio de una manera única, el proceso de socialización determina que ciertos aspectos de las imágenes mentales sean compartidos por grandes grupos" (Caneto, 2000: 9).

Los primeros antecedentes de estudio sobre percepción social del riesgo en las ciencias sociales se vinculan con trabajos realizados desde la geografía social o humana a partir de 1960 (Lavell, 1996; Puy Rodríguez, 2002) especialmente en torno a los desastres originados por inundaciones. A partir de 1970 y 1980 la psicología, sociología y antropología comienzan a incorporar el estudio de las percepciones sociales del riesgo.

Principalmente los trabajos realizados desde las ciencias sociales apuntan a analizar las diversas formas en que las personas o comunidades organizan su conocimiento sobre los riesgos, así como los factores que intervienen en el proceso perceptivo, con el propósito de explicar sus posteriores comportamientos y acciones en el espacio.

La percepción del riesgo involucra la presencia de los sentidos y del fenómeno percibido, de modo tal que "la percepción es el reflejo en la conciencia del hombre de los objetos y fenómenos, al actuar directamente sobre los órganos de los sentidos" (Petrowski, 1988: 261) y la particularidad de la percepción de riesgos es que "a la vez que se refleja el fenómeno, se concientiza la amenaza que representa para el individuo" (Rubinstein, 1967: 271).

Para Puy Rodríguez (2002: 65) abordar la percepción del riesgo desde las ciencias sociales "supone el estudio de las creencias, actitudes, juicios y sentimientos, así como el de los valores y disposiciones sociales y culturales más amplios que las personas adoptan frente a las fuentes de peligro". De esta manera, las percepciones del riesgo se basan en imágenes construidas a partir de la información proveniente del medio y de las experiencias previas ante una situación de riesgo.

Por lo tanto, interesa analizar la percepción que los residentes de Playa Magagna construyen respecto a las amenazas, particularmente por las implicancias que la imagen colectiva tiene en el comportamiento sobre el espacio y en la generación de transformaciones en el mismo.

\section{La encuesta como herramienta para el estudio de las percepciones.}

Para el análisis de la percepción social de las amenazas en Playa Magagna, se aplicaron encuestas personales a residentes de los tres principales asentamientos.

Mediante un muestreo probabilístico estratificado basado en el criterio de heterogeneidad espacial del área geográfica en estudio, se identificaron cuatro subuniversos de análisis asociados a las cuatros unidades espaciales geomorfológicas principales sobre las que se asienta la urbanización: acantilados inactivos, acantilados activos, terraza marina de acumulación y faja de acreción aluviocoluvial (ver figuras 2 y 3 ). 
Si bien cada sector urbanizado se encuentra expuesto a amenazas específicas, la encuesta incluyó la indagación de la totalidad de las amenazas existentes en el área de estudio, con la finalidad de identificar diferencias de percepción que pudieran surgir en el análisis de la información recolectada en campo. A continuación se describen las características de cada uno de los subuniversos (estratos) analizados. de edad.

El universo total de la muestra quedó constituido por una población de 153 personas mayores

\section{Características de los subuniversos}

Subuniverso 1 (Sub1): residentes permanentes y transitorios del sector de acantilados inactivos de las playas Bonita, El Faro y Cangrejales. Las viviendas ubicadas en este sector ocupan el pie de los acantilados inactivos (bardas), en la mayoría de los casos en directa exposición a procesos de peligrosidad (amenazas) de remoción en masa producto de la erosión hídrica-pluvial (ver figura 2).

Subuniverso 2 (Sub2): residentes permanentes y transitorios del sector de la terraza marina de acumulación. Este subuniverso de análisis se encuentra solamente en Playa Los Cangrejales. Las viviendas ubicadas allí no se exponen en forma directa a ningún tipo de amenaza, por el hecho de hallarse alejadas de las bardas y del frente marino (ver Figura 2).

Subuniverso 3 (Sub3): residentes permanentes y transitorios del sector de acantilados activos de playas Bonita, El Faro y Cangrejales. Las viviendas construidas en este sector se ubican sobre el frente costero, directamente expuestas a la erosión marina (ver figura 2).

Subuniverso 4 (Sub4): residentes permanentes y transitorios del sector de faja de acreción aluviocoluvial de playas Bonita, El Faro y Cangrejales. Dichos sectores corresponden a los más angostos de Playa Magagna, limitados por el frente marino y los acantilados inactivos (bardas). Las viviendas allí ubicadas se exponen a procesos de erosión desde ambos frentes: erosión marina e hídrica-pluvial (Ver figura 3).

\section{Análisis de la información}

Dado que la heterogeneidad espacial y el tipo de residencia fueron los dos criterios sobre los que se basó la realización de las encuestas de percepción, el análisis de los datos recabados, se realizó en función de los mismos, es decir, primeramente se analizó la información recolectada en cada uno de los subuniversos (de los tres asentamientos), y luego, dentro de cada subuniverso se analizó la información suministrada tanto por los residentes permanentes como temporarios, a fin de poder establecer si estos criterios están marcando o no una diferencia de percepción del riesgo. 
Revista Geográfica Digital. IGUNNE. Facultad de Humanidades. UNNE. Año 10. № 19. Enero - Junio 2013. ISSN 1668-5180 Resistencia, Chaco

Figura 2. Perfil de playa con unidades geomorfológicas y localización de subuniversos.

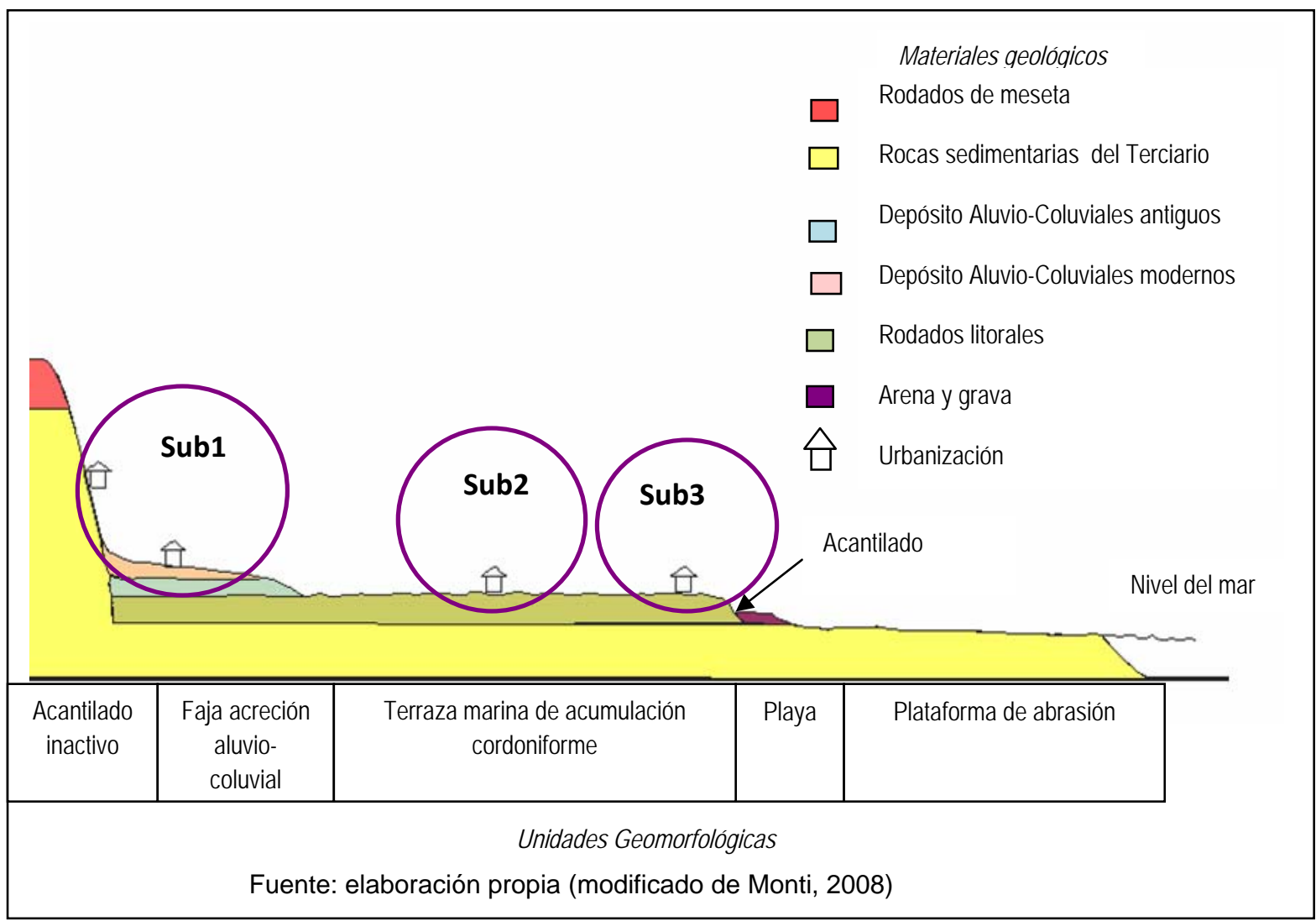

Figura 3. Perfil de playa con unidades geomorfológicas y localización del subuniverso 4.

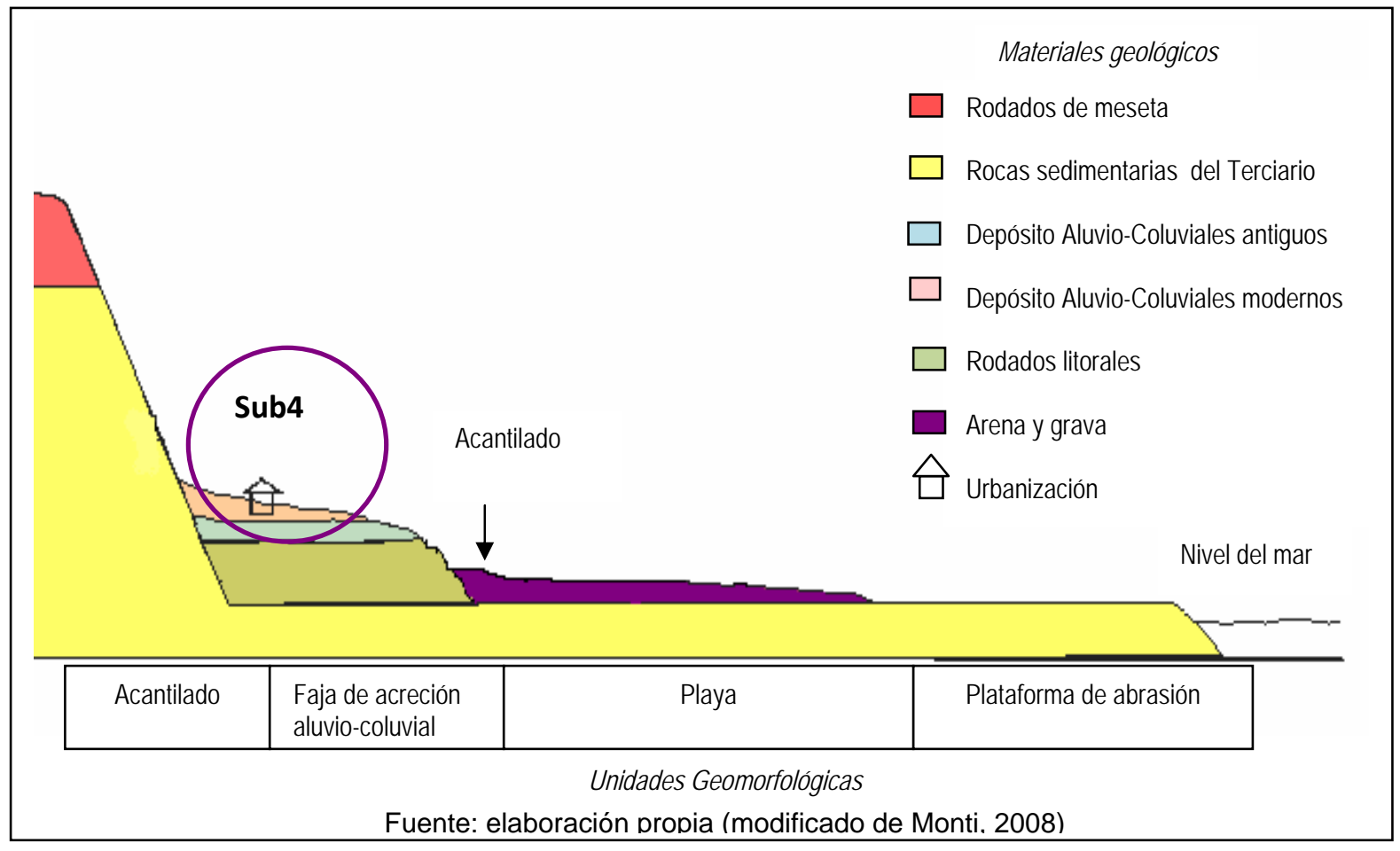

Publicado en formato digital: Dra. María Paula Ferrari. PERCEPCIÓN DE AMENAZAS EN UNA PEQUEÑA COMUNIDAD COSTERA DE PATAGONIA (ARGENTINA). Revista Geográfica Digital. IGUNNE. Facultad de Humanidades. UNNE. Año 10. No 19. Enero - Junio 2013. ISSN 1668-5180 Resistencia, Chaco. En: http://hum.unne.edu.ar/revistas/geoweb/default.htm 
Revista Geográfica Digital. IGUNNE. Facultad de Humanidades. UNNE. Año 10. № 19. Enero - Junio 2013.

ISSN 1668-5180 Resistencia, Chaco

\section{Resultados de las encuestas}

A partir del análisis de la información recolectada, la primera observación que surge es que las personas con residencia permanente perciben más amenazas que aquellas que residen temporalmente, principalmente por el hecho de haber experimentado algún evento dañino.

Respecto al área de acantilados inactivos de los tres asentamientos (subuniverso 1) tanto los residentes permanentes (el $89 \%$ de los encuestados) como los residentes temporarios (el $74 \%$ de los encuestados) perciben la remoción en masa asociada a eventos extremos de precipitación (erosión hídrica) como el tipo de evento más dañino. Por lo tanto, este subuniverso de encuestados percibe las amenazas existentes en el sector donde residen (ver cuadro 1). Dicha percepción está en directa vinculación con el derrumbe de laderas de las barrancas ocurrido en el mes de abril del año 1998, originado a partir de un evento extremo de precipitación que generó importante daños.

En el subuniverso 2, correspondiente a los residentes del sector de la terraza marina de acumulación de Playa Cangrejales exclusivamente (la urbanización en esta unidad geomorfológica no se encuentra en los otros dos asentamientos estudiados), si bien no se encuentran expuestos en forma directa a ninguna amenaza, por el hecho de estar alejados del frente marino y de los acantilados inactivos (barrancas), el total de las personas encuestadas con residencia permanente y más de la mitad del total de residentes transitorios encuestados, manifestaron percibir la remoción en masa asociada a la erosión hídrica como el tipo de amenaza que mayores daños genera (ver cuadro 1).

En el grupo de residentes del sector de acantilados activos (subuniverso 3) surge una diferenciación entre las playas analizadas. Los residentes permanentes y transitorios de playas El Faro y Cangrejales perciben los procesos de remoción en masa como el tipo de amenaza más importante en cuanto a los daños que genera. Por el contrario, las personas encuestadas en playa Bonita manifestaron percibir la erosión marina como la amenaza de mayor importancia a la que se exponen. Como se observa en el cuadro 1, este último grupo de personas encuestadas es el único que percibe el tipo de amenaza presente en el sector donde residen.

En el subuniverso 4 (sector de faja de acreción aluvio-coluvial), al igual que en el subuniverso anterior, surge una diferenciación en el análisis de los resultados, que en este caso no sólo se manifiesta entre los asentamientos sino también vinculada al tipo de residencia. Por un lado, los residentes permanentes de los tres asentamientos costeros perciben la remoción en masa como la amenaza que mayores daños genera (esta misma percepción es la que manifiestan los residentes transitorios de Playas Bonita y El Faro). Por otro lado, los residentes transitorios de playa Los Cangrejales, perciben la erosión marina como la amenaza de mayor importancia en cuanto a daños ocasionados en el sector. Al observar las dos columnas de la derecha del cuadro 1, vemos que en ningún caso se perciben las dos amenazas presentes en el sector, es decir, se percibe solo una de ellas (erosión marina o remoción en masa). 
Revista Geográfica Digital. IGUNNE. Facultad de Humanidades. UNNE. Año 10. № 19. Enero - Junio 2013. ISSN 1668-5180 Resistencia, Chaco

Cuadro 1. Síntesis de resultados sobre percepción de amenazas en Playa Magagna

\begin{tabular}{|c|c|c|c|c|}
\hline Subuniversos & $\begin{array}{l}\text { Sector y } \\
\text { tipo de } \\
\text { residencia }\end{array}$ & $\begin{array}{c}\text { Amenazas } \\
\text { indagadas } \\
\text { encuesta } \\
\text { Percepción } \\
\end{array}$ & $\begin{array}{l}\text { Amenazas } \\
\text { del sector }\end{array}$ & Amenazas percibidas \\
\hline $\begin{array}{c}\text { Sub } 1 \\
\text { (Bonita, Faro, } \\
\text { Cangrejales) }\end{array}$ & $\begin{array}{l}\text { Acantilado } \\
\text { inactivo } \\
\text { Residentes } \\
\text { permanentes } \\
\text { y transitorios }\end{array}$ & $\begin{array}{l}\checkmark \text { Erosión } \\
\text { hídrica } \\
\checkmark \text { Remoción } \\
\text { en masa } \\
\checkmark \text { Erosión } \\
\text { marina }\end{array}$ & $\begin{array}{l}\text { Erosión } \\
\text { hídrica } \\
\text { Remoción } \\
\text { en masa }\end{array}$ & $\begin{array}{c}\text { Remoción en masa asociada a } \\
\text { eventos extremos de precipitación } \\
\text { Residentes Per: } 89 \% \\
\text { Residentes Trans: } 74 \%\end{array}$ \\
\hline $\begin{array}{c}\text { Sub } 2 \\
\text { (Cangrejales) }\end{array}$ & $\begin{array}{c}\text { Terraza } \\
\text { marina de } \\
\text { acumulación } \\
\text { Residentes } \\
\text { permanentes } \\
\text { y transitorios }\end{array}$ & $\begin{array}{l}\checkmark \text { Erosión } \\
\text { hídrica } \\
\checkmark \text { Remoción } \\
\text { en masa } \\
\checkmark \text { Erosión } \\
\text { marina }\end{array}$ & Ninguna & $\begin{array}{l}\text { Remoción en masa asociada a } \\
\text { eventos extremos de precipitación: } \\
\text { Residentes Per: } 100 \% \\
\text { Residentes Trans: } 53 \%\end{array}$ \\
\hline $\begin{array}{c}\text { Sub } 3 \\
\text { (Bonita, Faro, } \\
\text { Cangrejales) }\end{array}$ & $\begin{array}{l}\text { Acantilado } \\
\text { activo } \\
\text { Residentes } \\
\text { permanentes } \\
\text { y transitorios }\end{array}$ & $\begin{array}{l}\checkmark \text { Erosión } \\
\text { hídrica } \\
\checkmark \text { Remoción } \\
\text { en masa } \\
\checkmark \text { Erosión } \\
\text { marina }\end{array}$ & $\begin{array}{l}\text { Erosión } \\
\text { marina }\end{array}$ & $\begin{array}{c}\text { Faro y Cangrejales: } \\
\text { Procesos de remoción en masa } \\
\text { Residentes Per } 62 \% \\
\text { Residentes Trans } 61 \% \\
\text { Bonita: Erosión marina } \\
\text { Residentes Per: } 100 \% \text { Residentes } \\
\text { Trans: } 67 \% \\
\end{array}$ \\
\hline $\begin{array}{c}\text { Sub } 4 \\
\text { (Bonita, Faro, } \\
\text { Cangrejales) }\end{array}$ & $\begin{array}{c}\text { Faja de } \\
\text { acreción } \\
\text { aluvio-coluvial } \\
\text { Residentes } \\
\text { permanentes } \\
\text { y transitorios }\end{array}$ & $\begin{array}{l}\checkmark \text { Erosión } \\
\text { hídrica } \\
\checkmark \text { Remoción } \\
\text { en masa } \\
\checkmark \text { Erosión } \\
\text { marina }\end{array}$ & $\begin{array}{l}\text { Erosión } \\
\text { marina } \\
\text { Remoción } \\
\text { en masa }\end{array}$ & $\begin{array}{c}\text { Residentes Permanentes de los } \\
\text { tres asentamientos: } \\
\text { el } 78 \% \text { percibe la remoción en } \\
\text { masa } \\
\text { Residentes Transitorios Bonita y } \\
\text { Faro: el } 70 \% \text { percibe la remoción } \\
\text { en masa } \\
\text { Residentes Transitorios } \\
\text { Cangrejales: el 79\% percibe la } \\
\text { erosión marina }\end{array}$ \\
\hline
\end{tabular}

Fuente: elaboración propia.

\section{Discusión de resultados}

El interrogante acerca del por qué algunas personas perciben ciertas amenazas en detrimento de otras o -como en el caso analizado- por qué algunos grupos perciben las amenazas a las que se exponen y otros no, puede explicarse tanto por aspectos inherentes al sujeto que percibe, como los que analiza Caneto (2000) referidos al sistema perceptivo y los procesos mentales de filtrado de la 
información; como así también a partir de las influencias que el contexto social y cultural ejercen en el proceso de construcción colectiva de una imagen sobre determinado fenómeno.

En este último sentido, al analizar las amenazas y las nociones de tiempo Evans (1994: 7) plantea que "el individuo se encuentra atrapado en una matriz de fuerzas socio-culturales, que reflejan la orientación de un valor dominante de pensamientos cortoplacistas". En el análisis de la percepción que la comunidad de Playa Magagna construye respecto a las amenazas, se observa una dominancia de los pensamientos de corto plazo, es decir, los residentes le dan mayor atención a las amenazas que puedan ocurrir en el tiempo presente, y no a las amenaza futuras.

En el mismo sentido, Pelegrina (2012) plantea que los sujetos que niegan la posibilidad de que un evento de peligro ocurra en el corto plazo, generan una sensación de seguridad interna en tanto reducen los niveles de incertidumbre. Por otro lado, la persona que acepta y reconoce que estas situaciones están latentes y pueden ocurrir en cualquier momento, "entran en sintonía con el estímulo amenazante, su percepción es más realista, alcanzan una adecuada conciencia del riesgo y son más capaces de movilizar los recursos necesarios para responder adaptativamente" (Pelegrina, 2012: 109). Esto último se comprobó que sucede con las percepciones del riesgo de la comunidad estudiada, dado que al reconocer la presencia de procesos de peligro y contextos vulnerables, no sólo son concientes de los riesgos a los que se exponen, sino que además, esto hecho posiciona a los actores activamente en la búsqueda de soluciones.

Asimismo, se observan rasgos de individualidad en la construcción de las percepciones sobre las amenazas, es decir, en muchos de los casos sólo se percibe las amenazas del sector donde la persona tiene su vivienda (en palabras de los encuestados "de mi sector") y no las de conjunto, o sea, las amenazas a las que se expone toda la comunidad.

Un aspecto distinto del tiempo, pero también esencial en el análisis de las amenazas que destaca Evans (1994) se vincula con las expectativas individuales sobre continuidad y cambio. Normalmente en la vida diaria las personas no piensan que pueden ocurrir cambios abruptos y radicales, sino que la mayoría cree que los cambios suceden en forma gradual o por lo menos con aviso anticipado. Esto mismo es lo que sucede con la percepción de las amenazas vinculadas a los procesos de erosión costera, por el hecho que los mismos presentan características de procesos de tipo penetrantes (en el sentido de Burton et al., 1978) debido a su baja magnitud y baja velocidad de aparición.

Por lo tanto, los residentes de Playa Magagna son cortoplacistas respecto a su percepción de las amenazas del lugar, y su decisión de permanecer en el sito indica que creen que los cambios ambientales ocurrirán lentamente o gradualmente.

\section{Conclusiones}

Si bien cada sector seleccionado para el estudio de las percepciones en Playa Magagna, se encuentra expuesto a peligros específicos, existe una percepción generaliza en la comunidad, en atribuir a los derrumbes de las laderas de los acantilados -procesos de remoción en masa- la causa principal de los daños ocurridos en el sector de barrancas y por lo tanto, se los percibe como los principales procesos de peligro. Lo anterior está indicando en que la comunidad no percibe todas las

Publicado en formato digital: Dra. María Paula Ferrari. PERCEPCIÓN DE AMENAZAS EN UNA PEQUEÑA COMUNIDAD COSTERA DE PATAGONIA (ARGENTINA). Revista Geográfica Digital. IGUNNE. Facultad de Humanidades. UNNE. Año 10. No 19. Enero - Junio 2013. ISSN 1668-5180 Resistencia, Chaco. En: http://hum.unne.edu.ar/revistas/geoweb/default.htm 
amenazas presentes en el área, sino que percibe otras áreas como las más expuestas a los riesgos. Por lo tanto, la percepción se focaliza en que es más probable que sean los demás quienes experimenten daños antes que uno mismo.

Por otro lado, resultó esencial no sólo conocer el imaginario que los pobladores de Playa Magagna tienen respecto a las amenazas naturales e inducidas antrópicamente, sino también el significado e importancia atribuido a los problemas costeros presentes en el sitio donde residen, dado que ello influye en su forma de actuar y, por lo tanto, de modificar el espacio o territorio donde se desenvuelven.

En la búsqueda de soluciones a problemas costeros de este tipo, la opinión de la comunidad debe ser considerara al momento de proponer acciones de gestión. Lograr una participación activa y continua de la comunidad de Playa Magagna, permitirá que la misma se apropie de las acciones que se propongan para manejar la problemática vinculada a las amenazas por erosión en el espacio costero analizado.

Considerando el postulado de Prades López y González Reyes (1996: 3) respecto a que “...la percepción social del riesgo debe entenderse como un instrumento para el desarrollo de políticas de prevención y gestión del riesgo...", se reconoce la importancia y necesidad de incluir el imaginario del riesgo que las comunidades construyen por dos aspectos fundamentales: para arribar a un diagnóstico integral y, al mismo tiempo, fomentar su articulación en los procesos de gestión.

\section{Referencias bibliográficas}

Burton, I.; Kates, R.; White, G., 1978. The environment as hazard. First Ed. Oxford University Press, New York.

Caneto, C., 2000. Geografía de la percepción. ¿Cómo vemos la ciudad? Lugar Editorial. Buenos Aires.

Cardona, O. D. 1993. Evaluación de la amenaza, la vulnerabilidad y el riesgo. Elementos para el ordenamiento y la planeación del desarrollo. En: Maskrey, A. (Ed). Los desastres no son naturales. (51-73). La Red de Estudios Sociales en Prevención de Desastres en América Latina. Bogotá, Colombia.

Evans, V. J. 1994. Percepción de riesgos y noción de tiempo. Desastres y Sociedad, № 3, Año 2. La Red de Estudios Sociales en Prevención de Desastres en América Latina.

Ferrari, M. P. 2012. Configuraciones del riesgo de erosión costera: transformaciones territoriales y percepción social en Playa Unión y Playa Magagna (Chubut, Argentina). Bahía Blanca, Argentina. Departamento de Geografía y Turismo. Universidad Nacional del Sur. 268 p. (Tesis de Doctorado en Geografía).

Google Inc. 2009. Google Earth (Version 5.1.3533.1731) [Software]. Disponible desde http://too.lazy.to.look.it.up/

Instituto Geográfico Nacional (IGN). 2012. Atlas Geográfico de la República Argentina. (CD-ROM). Argentina.

Lavell, A. 1996. Degradación ambiental, riesgo y desastre urbano. Problemas y conceptos: hacia la definición de una agenda de investigación. En: Fernández, A. (comp.) Ciudades en 
Riesgo. Degradación Ambiental, Riesgos Urbanos y Desastres. (12-43) La Red de Estudios Sociales en Prevención de Desastres en América Latina. Bogotá, Colombia.

Monti, A.J. 2008. Zonificación, usos y actividades en un espacio litoral patagónico de baja complejidad: proyecciones operativas en la gestión del riesgo. $X$ Jornadas Cuyanas de Geografía: La geografía frente a la necesidad de integrar territorios y voluntades. $1^{\circ} \mathrm{Ed}$. Facultad de Filosofía y Letras, Universidad Nacional de Cuyo. (18p.) 1 CD ROM. Mendoza.

Pelegrina, C. 2012. Percepción de los riesgos. En: Aneas de Castro, S. (coordinadora); Cattapan, S.; Pelgrina, C.; Torres, J.E. El hombre frente a los riesgos del ambiente. ISBN 978-950-605715-2. Editorial Universidad Nacional de San Juan. San Juan Argentina.

Petrowski, A. 1988. Psicología general. Editorial Pueblo y Educación, 1era Ed. La Habana, Cuba.

Prades López, A. y González Reyes, F. 1996. La percepción social del riesgo: algo más que discrepancias entre expertos y público. En: Padres López, A. (Ed.) Energía, tecnología y sociedad (56-62). Ediciones Torre. Madrid, España.

Puy Rodríguez, A. 2002. Percepción social del riesgo: dimensiones de evaluación y predicción. http://eprints.ucm.es/tesis/19911996/S/4/S4007501.pdf (17/06/2010). Tesis de doctorado.

Romero, G. y Maskrey, A. 1993. Como entender los desastres naturales. En: Maskrey, A. (Comp.) Los desastres no son naturales. La Red de Estudios Sociales en Prevención de Desastres en América Latina. Bogotá, Colombia.

Rubinstein, J. 1967. Principios de psicología general. Editora Revolucionaria. 1era. Ed. La Habana, Cuba. 